Juan Noemi C.

Profesor de Teología

Pontificia Universidad Católica de Chile

\title{
Vida y muerte: una reflexión teológico-fundamental
}

\author{
"No existen dos teologías, una sobre la vida y el \\ más acá, otra sobre la muerte y el más allá. Vida y \\ muerte se entrelazan y hermanan entre sí; por eso \\ han de ser pensadas conjuntamente" (1).
}

El tema de la vida tiene un significado teológico fundamental. Así lo sintetiza un texto cuya lectura me impresionó al iniciarme en mis estudios teológicos: "Dios, que vive, nos llama a la vida eterna. De un extremo a otro de la Biblia un sentido profundo de la vida en todas sus formas y un sentido muy puro de Dios nos revelan en la vida, que el hombre persigue con una esperanza infatigable, un don sagrado en el que Dios hace brillar su misterio y su generosidad". El artículo Vie del Vocabulaire de théologie biblique proseguía: "EL DIOS VIVIENTE. Invocar 'al Dios viviente' (Jos 3, 10, Sal 42, 3...), presentarse como el 'servidor del Dios viviente' (Dan 6,

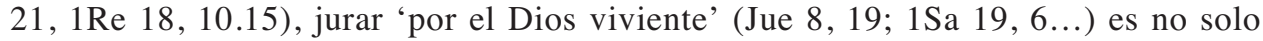
proclamar que el Dios de Israel es un Dios poderoso y activo, es también darle uno de los nombres que más estima (Núm 14, 21; Jer 22, 24; cf. Ez 5, 11...), es evocar su extraordinaria vitalidad, su ardor devorador 'que no se fatiga ni se cansa' (Is 40, 28), 'el rey eterno... ante cuya ira se es impotente' (Jer 10,10), el 'que perdura para siempre ...que nos salva y libera, obra signos y maravillas en los cielos y la tierra' (Dan 6, 27s). La estima que la Biblia asigna a este nombre es signo del valor que para ella tiene la vida" (2). La fundamentalidad de la vida como tema de la teología se radicaliza todavía más si recordamos lo que nos enseña un erudito y penetrante especialista del Antiguo Testamento. Claus Westermann, tratando de clarificar cuál es el estatuto epistemológico de la teología veterotestamentaria, introduce al tema en los siguientes términos: "Hablar de Dios es hablar del todo. Una característica del Antiguo Testamento consiste en que su discurso se refiere al todo. Empieza con el principio del mundo y la humanidad en la creación, y anuncia en las Apocalipsis el fin del mundo y de la humanidad. Incluye principio y fin, habla de Dios en la

(1) "Presentación" al Nº 998 en Homenaje a J. L. Ruiz de la Peña de la revista Sal Terrae 85 (1997) 90

(2) A. A. Viard - J. Guillet, Art. Vie, en Vocabulaire de Théologie Biblique , X. Léon - Dufour Dir., París 1962, 1106-1107. 
medida que habla del todo" (3). A continuación, Westermann establece una distinción que le permite determinar una dimensión específica de la teología veterotestamentaria: "Del todo es posible hablar de dos maneras fundamentalmente diversas, como lo que es o como lo que acontece; como lo existente o como lo aconteciente. En el Antiguo Testamento el todo es comprendido como lo aconteciente, como lo que acontece desde la creación al fin del mundo. Lo aconteciente predetermina lo existente" (4).

Según lo anterior tendríamos que la vida no se estipula como un tema teológico más, como un tópico objetualmente cuantificable y paralelizable a otros, sino que, primigeniamente, del mismo Dios se habla como de la vida (5), como del "Dios viviente", como del "todo aconteciente". No cabe hablar de la vida sin hablar de Dios y tampoco cabe hablar de Dios sin hablar de la vida. Vida y Dios se postulan como dimensiones de la realidad que se condicen. Hablar de la vida comporta inexorablemente hablar de Dios como realidad fundamental que acontece en cuanto vida, la cual, por su parte se sustenta en Dios mismo como en su principio y fin, como en su fundamento y futuro. La vida es en Dios y Dios acontece en la vida.

\section{VIVIR: SER ACONTECIENDO}

De la fundamentalidad teológica con que se habla de la vida en la Biblia y que apunta a la conjunción de una doble dimensión totalizante y dinámica, absolutizante y evenencial a la vez, deriva un complejo requerimiento. El mismo Westermann plantea que el discurso teológico prototípico del judeo cristianismo no se ha respetado en Occidente: "En la teología occidental el todo es comprendido como el todo de lo existente (Ganze des Seienden). Dios mismo puede ser entendido como lo existente (das Seiende). Pero al hablarse de Dios como del ens o el summum ens, entonces es degradado como criatura ya que todo existente es per definitionem ser

(3) C. Westermann, Das Alte Testament und die Theologie, en G.Picht Ed., Theologie.Was ist das?, Ulm 1977, p. 49 : "Von Gott reden heist von Ganzen reden. Eine Eigenart des Alten Testament besteht darin, dass sein Reden das Ganze umfasst. Es setzt mit dem Beginn von Welt und Menschheit in der Schöpfung ein, und es kündigt in den Apokalypsen das Ende der Welt und das Ende der Menschheit an. Es umfasst Anfang und Ende; es redet von Gott, indem es vom Ganzen redet". A reglón seguido Westermann se explaya: "Das Alte Testament umfasst zwischen Anfang und Ende alles, was die Welt und was in der Welt ist; es umfasst die Ganze Menschheit und den ganzen Menschen in seinem Daseinsbogen von der Geburt bis zum Tod. Es redet von Himmel, Erde und Gestirnen, von Blumen und Bäumen, von Strömen und Bächen, von Tieren aller Art, von Meeren und Wüsten. Es redet von der Menschheit in allen Völkern und in allen Rassen; nahe beieinander stehen die alle damals bekannten Völkern umfassende Völkertafel und die Verheissung an Abraham: In dir sollen sich segnen alle Geschlechter der Erde. Es redet vom einzelnen Menschen in seinem ganzen Daseinsbogen: die ganz kleinen Kinder und die ganz alten Leute gehören dazu, die Kranken und die Gesunden, die Freien und die Gefangenen, die Könige und die Hausfrauen. Indem das Alte Testament von diesem grossen Ganzen redet, redet es von Gott. Es könnte nicht von Gott reden, würde es nicht von diesem grossen Ganzen reden”.

(4) O.a.c., 49-50 : "Vom Ganzen kann auf zwei grundverschiedene Weisen geredet werden: es kann verstanden werden als das, was ist, oder als das, was geschieht; als das Seiende oder als das Geschehende. Im Alten Testament ist das Ganze als Geschehendes verstanden, das von der Schöpfung bis zum Weltende Geschehende. Das Geschehende ist dem Seienden vorgeordnet...".

(5) En el mismo sentido sintetiza H. Hübner que bíblicamente "vida es un concepto relacional" (Relationsbegriff), Art. Leben, en Historisches Wörterbuch der Philosophie 5, Basilea 1980, 57. 
creado" (6). Es así como -prosigue Westermann- "la preeminencia de lo existente sobre lo aconteciente se manifiesta en el vocabulario usual de la teología que ininterrumpidamente se usa hasta el día de hoy. Lo usual para referirse al discurso sobre Dios, Cristo, los actos salvíficos de Dios, el pecado y el futuro es hacer una unión con la palabra logos: cristología, soteriología, antropología, escatología, etc. Al establecerse tal unión, claramente logos no se entiende en el sentido hebreo de dabar, sino en el sentido que logos tiene en griego. Se trata de un discurso referido a lo existente, no a la palabra que acontece entre personas".

La denuncia de Westermann nada tiene que ver con el reclamo romántico de un aislado especialista en el Antiguo Testamento, sino que resuena como otra voz más que se suma a un coro de pensadores que durante la modernidad tematizan una "crisis de la metafísica occidental" y más puntualmente se abocan a una "crítica de la ontoteología". No es pertinente aquí explayarse en este tema. Baste, en inmediata referencia al significado teológico fundamental de la vida en tanto tema de la teología, recoger el desafío que la "crisis de la metafísica occidental" le plantea hoy a una teología auténticamente dogmática. Como bien resume A. Gesché (7), "la crisis de la metafísica occidental" debe calibrarse de acuerdo a la importancia del apoyo que históricamente la teología ha buscado y encontró en la metafísica: "La orientación general de la teología fue una 'patriótica' confianza en los recursos de la razón filosófica, de la que hizo su principal auxiliar. Ciertamente la teología no puede prescindir de esta mediación, pero tampoco puede hacer uso de ella ignorando los cambios que afectan al destino de la metafísica en su propio campo". Ahora bien, el cambio decisivo que se ha operado es el que representa "la crítica de la ontoteología que considera a Dios como ser supremo y al ser bajo la forma del ente, sin hacer justicia a Dios ni al ser. Esta crítica de la ontoteología, expuesta por Kant, proseguida por Nietzsche y llevada a término prácticamente con Heidegger, puede llevarnos a una mejor apreciación de nuestros presupuestos, a un mayor dominio de los derechos propios de la fe y a una nueva aventura del Ser en el espíritu humano... Al señalar que la metafísica occidental había olvidado la diferencia entre el ser (en su primordial y permanente fontalidad) y el ente (una forma de ser en una determinada manifestación fenoménica), Heidegger ha mostrado el camino de una nueva ontología. El ser no debe ser descifrado a partir del ente (meta-física), aunque sea el ente supremo (onto-teología), porque este no ha de ser considerado como un simple ente, sino a partir de sí mismo (onto-logía)".

Con lo anterior Gesché no se está resignando a un fin de la metafísica o una burda muerte de Dios, sino que aclara que la "deconstrucción de la metafísica clásica no es de ningún modo la destrucción de un proyecto tan viejo como el mundo e indispensable a su pensamiento, sino la invitación a una reconstrucción en la que el ser vuelve a ser escuchado en su lugar natal y en su automanifesta-

(6) O.a.c., 50 .

(7) “Teología Dogmática”, en Iniciación a la práctica de la teología. Tomo I. B. Lauret- F. Refoulé Eds., Madrid 1984, 274.

(8) O.a.c.475. Nos hemos permitido corregir la traducción castellana utilizada que traduce incorrectamente déconstruction por demolición. En el mismo sentido H. Hoping señala que la controversia sobre la metafísica no se puede reducir a la alternativa "fin de la metafísica o vuelta a la metafísica", "Das Absolute in der Differenz des Seins", en D.Hattrup- H.Hoping Eds., Christologie und Metaphysikkritik, Münster 1989, 2. 
ción" (8). En realidad, más que hablar de una "demolición" (como lo hace la traducción castellana que hemos corregido), sería más propio hablar de un intento de superación (Aufhebung, Überwindung) de lo que ha sido un determinado itinerario histórico del pensamiento metafísico. No se trata de un acabamiento, sino lo que se perfila es una renovación en la cual los límites que se evidencian en la historia de la metafísica gestada en Grecia se superen en una "metafísica histórica". Así ya lo planteaba Schelling (9) y así lo sostiene el mismo Heidegger (10). A mi parecer, si tiene sentido situarse en una época postmetafísica y postular un "pensar postmetafísico"como lo hace Habermas (11), este reconocimiento se torna un suicidio del pensar si se asume como un destino ciego y consumado y no como un incentivo kairótico para pensar más profunda y positivamente la historia y la libertad.

\section{VIVIR Y MORIR}

Hacerse cargo de la complejidad del discurso bíblico sobre la vida no se resuelve en todo caso con el mero postulado de un enfoque metafísico e histórico a la vez, sino que apela a un requerimiento todavía más comprometedor y desafiante. Nos obliga a hablar de la muerte más allá del silencio resignado ante la misma, más allá de esforzarse por constatarla tan lógica como impávidamente como mera negación contradictoria de la vida. Hablar de la vida con sentido no solo requiere haber pensado la misma vida, sino también el significado de la muerte en referencia a la unidad de la diferencia que la sostiene positivamente como término contradictorio de vida. Imposible hablar de la vida sin hablar de la muerte y viceversa (12). El discurso que explícitamente se refiere a la vida subcontrario e implícitamente se está refiriendo a la muerte y viceversa. Hablar de la vida implica, sí o sí, referirse a la

(9) Al respecto me permito recordar lo que señalara a propósito del Schelling tardío: "El conocimiento propio de la filosofía positiva supera y es la perfección de la negativa, en la medida que deja el campo de lo meramente posible y se confronta y piensa lo realmente existente. La filosofía positiva trasciende la esfera de las meras esencias y las posibilidades; se refiere a lo concreto, es una 'filosofía histórica' (XI, 571). Ella tiene su condición de posibilidad en cuanto lo primero (Prius) absoluto al cual queda confrontada la razón es conocido como contenido de sí misma, o como expresa Schelling: 'Dios es lo trascendente que se ha hecho inmanente' (XII, 170). La 'Filosofía de la Revelación' queda, así, antecedentemente delimitada como un ensayo de filosofía de lo real y concretamente existente, se perfila como una metafísica de la historia y como una historia del ser". "Sobre la vigencia teológica de Schelling", en La fe en busca de inteligencia, Santiago 1993, 63-64.

(10) "No podemos deshacernos de la Metafísica como nos deshacemos de una opinión. De ninguna manera se la puede dejar atrás como una doctrina en la que ya no se cree y que nadie defiende. El hecho de que el hombre, como animal rationale...tenga que vagar errante por el desierto de la desertización de la tierra podría ser un signo de que la Metafísica se manifiesta a partir del ser mismo, y de que la superación (Überwindung) de la Metafísica tiene lugar en tanto que torsión (Verwindung) del ser". "Superación de la Metafísica", en Conferencias y artículos, Barcelona 1994, 64. Sobre este punto se puede leer con provecho la introducción de Arturo Leyte a la edición bilingüe de M. Heidegger "Identidad y diferencia. Identität und Differenz", Barcelona 1990, 7-54.

(11) Conf. J. Habermas, Nachmetaphysisches Denken, Frankfurt am Main 1988.

(12) Como lo señala X. Zubiri "El problema de la muerte es el problema de la pertenencia intrínseca de la muerte a la vida física y real", Sobre el Hombre, Madrid 1986, 660. 
muerte y viceversa. No estamos aludiendo solo a una abstracta coincidencia lógica o matemática entre términos contradictorios. A juicio de $\mathrm{N}$. Luhmann lo que le da sentido al sistema religioso es un esquema que se articula en base a "la diferencia de inmanencia y trascendencia" (13). Ahora bien, me parece que esta diferencia remite a una diferenciación entre vida y muerte que a nivel de la experiencia personal es antecedente. La registra con elocuencia Franz Rosenzweig, en el primer párrafo de "La estrella de la redención" (14): "Por la muerte, por el miedo a la muerte empieza el conocimiento del Todo. De derribar la angustia de lo terrenal, de quitarle su aguijón venenoso y su aliento de pestilencia al Hades, se jacta la filosofía. Todo lo mortal vive en la angustia de la muerte; cada nuevo nacimiento aumenta en una las razones de la angustia, porque aumenta lo mortal. Pare sin cesar el seno de la infatigable Tierra y todos sus partos son puestos a la merced de la muerte: todos aguardan con temor y temblor el día de su viaje a lo oscuro... Por más que el hombre se defienda de los tiros al corazón de la muerte ciegamente inexorable escondiéndose como gusano en los repliegues de la tierra desnuda percibe a la fuerza y sin remedio lo que de otro modo nunca percibe: que su Yo de morir, solo sería un Ello, y grite él entonces su yo, con todos los gritos que aún contiene su garganta, a la cara de lo Inexorable que le amenaza con ese exterminio inconcebible, en semejante trance sonríe la filosofía su vacía sonrisa y con el índice señala a la criatura -cuyos miembros entrechocan de angustia por el más acá- hacia un más allá del que ella nada quiere oír. Pues el hombre no quiere escapar de no sé qué cadenas: quiere quedarse, permanecer, quiere vivir". El mismo Heidegger explicando el sentido de "ser para la muerte" aclara que "no se trata de disolver al hombre en la muerte y darlo por mera nulidad, sino viceversa: introducir la muerte en el ser ahí en su abismosa amplitud y así medir plenamente el fundamento de la posibilidad de la verdad del ser (Seyn)" (15).

De acuerdo al planteo anterior tendríamos que un discurso coherente sobre la vida implica hacerse cargo de un dinámico condecirse de la vida y Dios que no excluye la muerte como abstracta realidad contradictoria de la vida, sino que la enfrenta como un concreto tener que y la asume consecuentemente como condicionante, no solo negativo, de un discurso con sentido sobre la vida. Como bien lo sintetiza Ruiz de la Peña en un escrito póstumo: "La muerte atañe esencialmente a la vida... El hombre es un ser finito, y esa finitud es la nota más abarcadora, el distintivo más infalsificable de la condición humana. De impedir su camuflaje se encarga la muerte. La muerte sería la evidencia empírica, física, brutalmente irrefutable, de esa cualidad metafísica de la realidad -de la realidad humana en este casoque llamamos "finitud"” (16). De allí que para este teólogo castellano: "La pregunta sobre la muerte es en primer lugar la pregunta sobre el sentido de la vida" (17). Es este mismo requerimiento de pensar la unidad que sostiene la diferencia de vida y

(13) Ver "Die Ausdifferenzierung der Religión", en Gesellschafsstruktur und Semantik B.3 1989, 298 y ss.

(14) Salamanca 1997, 43-44.

(15) Aportes a la Filosofía. Acerca del evento (traducción Dina Picotti), Buenos Aires 2003, 232.

(16) J. L. Ruiz de la Peña, "La muerte, fracaso y plenitud" en Sal Terrae 85 (1997) 94-95.

(17) A.a.c. 96. Al respecto se puede consultar con provecho J. Grondin, Del sentido de la vida. Un ensayo filosófico, Barcelona 2005. 
muerte, el que, hace ya varios años, se me hacía presente al indagar sobre el significado que puede tener hablar de una "teología de la muerte" (18).

\section{VIVOS ANTE LA MUERTE}

La muerte se nos presenta como lo más cierto que le aguarda a nuestra vida y, al mismo tiempo, como aquello que nos saca o nos enajena de la vida. Tal es la situación que condiciona las posibilidades de nuestro discurso sobre el tema.

En sí misma la muerte es indefinible, simplemente porque definir algo es un acto de dominio sobre lo definido: para definir la muerte tendríamos que dominarla. Y sabemos que, en realidad, es ella quien nos domina a nosotros (19). No es posible hablar de la muerte como de una experiencia hecha. Los que realmente han hecho esta experiencia, ya no nos hablan. Mientras estamos vivos, solo sabemos de la muerte por el testimonio mudo y opaco de otros, no por nosotros mismos. Al referirnos a ella, decimos cosas en relación a algo que situamos como futuro o posibilidad. Cuando dicho futuro o posibilidad se actualiza, dejamos de hablar y, solo entonces, hacemos la experiencia de la muerte. Visualizamos, por tanto, a la muerte como una realidad que nos aguarda. Esta "futuridad" dificulta nuestra reflexión en dos sentidos: primero, porque determina un tipo de discurso referido a una experiencia que nos es todavía ajena y que, desde ese futuro, nos perturba y nos incita a pensarlo como un destino ignoto y cuestionador a la vez. En segundo lugar, porque no necesitamos definir, con Heidegger, nuestra realidad como "ser-para-la-muerte" para reconocer un dato de por sí innegable: el tener que morir, propio de todo hombre.

Esta experiencia básica del tener que morir equivale a captar que nuestra vida se va a terminar. Ello nos permite situar y captar la muerte como "acabamiento de la vida". Ahora bien, el tomar conciencia de esa realidad que sucede a la "inconciencia" del estar puramente vivo no es neutra, sino que aparece como "conciencia infeliz". Como dice un proverbio latino ante mortem nemo beatus (nadie es feliz ante la muerte). Estar vivo pero tener que morir no es la constatación apática de un hecho normal y natural, sino que despierta una tensión entre la experiencia de estar vivos -que vivenciamos como un bien al que institivamente nos aferramos-y el tener que morir como un destino que nos asusta y despierta, por ende, en nosotros rechazo.

El tener que morir nos agrede como algo que, siendo una realidad relativa a la vida, constituye, a la vez, para ella, la más intolerable heterogeneidad. Para el hombre, vivir es ser, y morir es dejar de ser. La muerte equivale al no-ser. Es cierto que biológicamente la muerte del hombre no constituye sino un fenómeno natural. Pero, debido al nexo que se da entre vida y ser, ontológicamente la muerte constituye para el hombre la alienación radical: es decir, el hecho de que, habiendo sido, ocurra para él un instante en que "deja de ser".

(18) Cf. "En torno a una teología de la muerte", en El mundo creación y promesa de Dios, Santiago de Chile, 1996, 333-407.

(19) Conf. E. Jüngel, Tod, Stuttgart 1985, 11. 
Lo que los biólogos nos pueden decir sobre la muerte solo da razón de un aspecto o dimensión de la experiencia humana del indefectible tener que morir. En realidad, desde el punto de vista biológico la muerte constituye un fenómeno absolutamente natural y requerido por el ciclo vital mismo. La muerte no es más que el resultado de una ordenación natural que se inscribe en la constitución genética de cada individuo. Sin contar, obviamente, con los factores externos, la muerte de cada persona humana, nos dice la biología, está preprogramada. Biológicamente, la muerte no es otra cosa que la descomposición de un organismo y la pérdida de los nexos que necesariamente se dan en una determinada estructura orgánica.

Para la biología la muerte es un fenómeno absolutamente natural que se define negativamente en relación a la vida como "cesación" de la misma (20). Ahora bien, cuando el experimentarse vivo equivale a experimentarse siendo, la muerte se presenta como cesación del ser. Es precisamente en esta dimensión del tener que morir humano donde la biología y los ensayos que consideran la muerte en su sola "naturalidad", encuentran un límite. Por de pronto, no se asume la historicidad del morir: la inevitabilidad de la muerte no es un acontecimiento desligado, sino que se refiere a un sujeto que es capaz de experimentarse como libre, esto es, como sujeto de una historia, a la vez que como ser constantemente amenazado por un destino de no-ser. La muerte pone en cuestión el sentido que pueda tener la vida humana.

La etnología y la psicología han analizado a fondo y en sus más diversas implicancias este deseo de vivir. Para los primitivos, la muerte, a pesar de la proximidad permanente e inmediata con que se la experimenta, no tiene nada de natural, sino que constituye una "anomalía" que es necesario explicar a través del mito (21). Freud, por su parte, afirma que, en el fondo, "nadie cree en su propia muerte" o, lo que es lo mismo, "en lo inconsciente todos estamos convencidos de nuestra inmortalidad", con lo cual pone de manifiesto el rechazo o el sempiterno horror a morir del hombre. La muerte no es para el hombre un desenlace normal y natural, por más que sepa que se trata de una "ley de la vida". Psicológicamente se constata una "paradojal actitud de negación ante la muerte del ser humano ... la paradoja se constituye como la imposibilidad de aceptar nuestra muerte en nuestro inconsciente, a pesar de que nuestro aparato perceptivo nos informa continuamente de la absoluta realidad e inevitabilidad del suceso" (22).

Que el hombre no se conforma ni se da por satisfecho con una explicación de la muerte como fenómeno natural, lo pone de manifiesto su constante búsqueda de la inmortalidad como "bien que conviene a su ser". La búsqueda de inmortalidad es un leitmotiv religioso-cultural: "Es probable que la creencia de que se sobrevive a la muerte física sea instintiva en el hombre; los ritos funerarios así lo atestiguan desde los albores de la civilización" (23).

(20) C. Favarger, El sentido biológico de la muerte, en El hombre frente a la muerte, Buenos Aires 1964, 9; H. Holz, Art. Tod, en Handbuch philosophischer Grundbegriffe V, 1514.

(21) "En el pensamiento primitivo, la muerte, generalmente no se considera como un acontecimiento natural...", S.G.F. Brandon, Art. Muerte, en Diccionario de Religiones Comparadas, Madrid 1975, 1055. Conf. en el mismo sentido A. Bertholet - C.M. Edsman, Art Tod und Totenreich, religionsgeschichtlich, en Religion in der Geschichte und Gegenwart VI, 908-911.

(22) J. F. Jordán, La muerte en la relación médico-paciente, en Ed. M. Gomberoff - J.P. Jiménez, Psiquiatría, Santiago 1982, 613.

(23) S.G.F. Brandon, Art. Inmortalidad, en Diccionario de Religiones Comparadas, Madrid 1975, 815. 
El que la muerte no constituye para el hombre un fenómeno natural, no es un fenómeno constatado tan solo por la psicología y la etnología. El rechazo a la muerte no proviene de un apego meramente animalesco a la vida en cuanto proceso vegetativo y sensitivo, sino que se funda en la experiencia que el hombre hace de sí como ser libre. Siendo la libertad un momento necesario y fundante del ser del hombre, la muerte, entonces, no cabe. Morir equivale a no-ser, a dejar de ser, y la libertad -en cuanto dimensión propia de la existencia humana- consiste en estar abierto infinitamente y sin límites en el ser. Al experimentarse como libre, el hombre transgrede la necesidad natural de morir. Cuando ama, la incongruencia de la muerte es todavía más nítida. Recordemos la afirmación de Gabriel Marcel: "Amar a un ser es decirle: "tú no morirás'" (24). Porque piensa y ama, el hombre se experimenta en el ser con una conveniencia a la que repugna el definitivo dejar de ser: la muerte. El que muere es un ser que al morir deja de ser, habiéndose experimentado con un ansia infinita de vida y con una apertura definitiva y permanente a ella (25).

Para la vida del hombre, la muerte es un absurdo y un sinsentido. En realidad, en sí misma la muerte del hombre no tiene sentido, no es más que "dejar de ser". Cuando alguien muere pierde la capacidad de relacionarse con el mundo exterior y nada me permite pensar que ello no sea, para la persona, más que la expresión de la pérdida de relación consigo misma y, por tanto, de dejar de ser.

\section{LA MUERTE Y DIOS}

La dificultad de un discurso sobre la muerte es todavía mayor si pretende articularse como teológico (es decir, de una realidad que concierna a Dios), ya que si hay algo ajeno y extraño al Dios de Jesucristo es, precisamente, la muerte. La tradición bíblica es taxativa al respecto. En la Biblia la muerte es equivalente a lejanía y ausencia de Dios. Yavé vive (Dt 5, 26; Sal 18, 47), es "la fuente de la vida" (Sal 36, 10) y el que sostiene en ella (Sal 104, 29 s). La muerte, en cambio, es algo radicalmente ajeno a Dios: no ha sido creada por Él (Sab 1, 13); por el contrario, Dios creó al hombre como "ser vivo", a la sombra del "árbol de la vida" (Gén 2, 7-9).

La muerte es, pues, una realidad ajena a Dios. El lugar de los muertos es concebido como la máxima distancia representable con respecto a Él. Este lugar, llamado Sheol, es descrito en el Antiguo Testamento como la tierra sin retorno (Job 3, 11ss; 7, 9 s), la tierra del olvido (Sal 88, 7; Sir 9, 5), el silencio total (Sal 94, 17) o, simplemente, la oscuridad (Sal 88, 7; Job 18, 18). El Sheol y los muertos no alaban a Yahvéh (Sal 115, 17; Is 38, 18s) y tampoco Dios se acuerda de los muertos $($ Sal 88,6$)$. Esto no significa que la muerte sea postulada como una suerte de "otra divinidad", esto es, como un poder paralelo al Dios de la vida (Am 9, 2; Sal 139, 8).

(24) La mort de demain, París 1931, 161.

(25) Como bellamente lo ilustran dos relatos maestros de la literatura latinoamericana que se analizan con finura en A. Toutin, "De una vida amenazada a una vida anhelada. Atisbos a una teología de la vida en diálogo con la literatura. Dos figuras imaginativas que hablan desde el otro lado de la vida. La Amortajada (1938) de María Luisa Bombal (1910-1980) y Pedro Páramo (1955) de Juan Rulfo (1917-1986)" en Teología y Vida. 
Lo que se quiere expresar es que la muerte y los muertos designan la lejanía del único Dios, que se define, de un modo unívoco, precisamente como "Dios de la vida" (Sal 6, 6; 30, 10; 88, 6; 115, 17; Is 38, 11; Sir 17, 27ss).

En la perspectiva del Antiguo Testamento queda, pues, cercenada la posibilidad de una teología de la muerte en sentido propio, ya que referirse a dicha realidad comporta, precisamente, hablar de lo que no es Dios ni concierne a Él.

Pero esta dificultad no proviene solo del horizonte teológico de la Biblia. Surge, también, cuando para referirnos a Dios lo hacemos desde una ontoteología del ser absoluto, como ha sido lo predominante en la historia de la teología. ¿Qué sentido tiene plantear una teología de la muerte cuando nos estamos refiriendo a una "incommutabilis substantia" (D.H. 3001) en relación a la cual la muerte es impensable? Si la muerte no concierne a Dios, ¿qué sentido tiene hablar de una "teo-logía de la muerte"?

Ciertamente, el motivo de la dificultad es diverso para el creyente yavista que para el pensador que comprende a Dios como un ser inconmutable. En el primer caso se trata de una contradicción positiva entre vida y muerte, entre lo que es Dios y lo que no es Dios. En cambio, la dificultad para una teología de la muerte en la perspectiva de una ontoteología del ser absoluto, reside en la falta de referencia entre la inmutabilidad y la apatheia de Dios, y la mutabilidad y el pathos implicados en la muerte.

Pero, en cualquier caso, ambas perspectivas confluyen a un mismo cuestionamiento: si el Dios de Jesucristo no tiene nada que ver con la muerte, si ella no le afecta, entonces solo hablamos de "teología de la muerte" en sentido impropio. En este sentido y bajo esta perspectiva se han escrito muchas reflexiones, con el propósito de iluminar y de consolar al hombre como ser enfrentado inexorablemente a semejante destino. Entonces se trata de consideraciones teológicas en referencia a la muerte, pero no exactamente de una teología de la muerte. Estrictamente debe hablarse de una teología de la muerte solo si tiene algún sentido hablar de una muerte de Dios. El desarrollo de la teología en el siglo pasado testimonia de diversos ensayos que se aventuran en rescatar un sentido teológico positivo en el discurso sobre una muerte de Dios que no es del caso reseñar aquí (26) uno por uno. Baste indicar que se trata de un discurso crítico y reactivo, que cuestiona los límites de una determinada forma de pensar y de un determinado esquema metafísico que han predominado en la teología. Es innegable que estos ensayos comportan una crítica y el distanciamiento de una "teo-ontología griega del "ser Absoluto", como lo reconoce Von Balthasar (27).

Para algunos, esta criticidad puede ser, desde un principio, motivo de escándalo y de rechazo del discurso posthegeliano sobre la "muerte de Dios". Pero tal rechazo no es justificado, pues confunde el pensar cristiano con una determinada metafísica. La función de la teología no es sancionar un determinado esquema filosófico, sino anunciar el Evangelio. De todos modos, no se puede prescindir, sin más, de los resultados a los que llega una ontoteología griega con respecto al tema de la inmutabilidad e impasibilidad de Dios. El discurso crítico no es inválido por ser

(26) Lo hago en El mundo Creación y promesa de Dios, Santiago de Chile, 338-355.

(27) Theodramatik IV Das Endspiel, Einsiedeln 1983, 191. 
crítico, pero para serlo consecuentemente debe ser también autocrítico y consciente de su propio condicionamiento histórico. En caso contrario, se desvirtúa como mera reacción.

La teología de la muerte de Dios constituye un discurso moderno, en el sentido más amplio del término: es decir, asume una problemática propia del pensar postilustrado, como bien lo muestra el planteo de Hegel. En otras palabras, es un discurso que pretende ser responsable de la modernidad, vale decir, de la experiencia de realidad que hace el hombre moderno y, más específicamente, de la muerte como sinsentido y absurdo.

Responder a las preguntas y cuestionamientos de la razón moderno-contemporánea es una tarea que la teología desatendió durante mucho tiempo, y que ahora más que nunca constituye un desafío urgente. En ese sentido, el discurso sobre la muerte de Dios empieza a llenar un vacío. Pero responder no significa solamente "sancionar", sino que también implica corregir, iluminar. Este aspecto coincide con el requerimiento autocrítico ya señalado anteriormente.

El discurso de la muerte de Dios tiene también una pretensión sintética, en la medida en que pretende mediar entre un esquema teísta y un ateísmo determinado. Se pretende responder al homme revolté de Camus, que ha dejado de ver en la afirmación de Dios una respuesta al problema del mal y de la muerte. Por otra parte, pretende superar los límites de un determinado esquema teísta que no logra mediar entre el mal y Dios, y que para afirmar a Dios tiene que banalizar el mal como mera carencia.

Como se podrá ver en el siguiente acápite, el de la muerte de Dios, se explicita como un discurso cristológico. Es así como varios de los teólogos que hablan de la muerte de Dios ven en Lutero a un precursor. Y con justa razón. La condición de posibilidad de este discurso no reside en una nueva delimitación de la divinidad lograda ontológicamente, sino en una reconsideración de la muerte de Jesucristo. Se trata, pues, de una aproximación a Dios per passionem et crucem conspecta (consideradas la pasión y la cruz), como pide Lutero al digne theologus (verdaderamente teólogo). Pero este radical cristocentrismo no debe llevar a un reductivismo fideísta, sino que, para ser realmente cristológico, debe mediar con aquello que la razón logra captar como Dios per ea quo facta sunt (28) (por medio de las cosas creadas), dado que el Dios que muere el Viernes Santo es el mismo que nos crea.

Por último, la teología de la muerte -en sentido estricto- es un discurso trinitario. Sin tener que avalar el planteo moltmaniano, resulta innegable el aporte que puede tener este tema para la requerida renovación de la teología trinitaria (29). Parafraseando a Moltmann, Forte escribe "Historia del Hijo, del Padre y del Espíritu, la cruz es historia trinitaria de Dios... La figura trinitaria se ofrece sobre la cruz en la unidad del Hijo que se entrega, del Padre, que lo entrega, del Espíritu, entrega-

(28) Para Lutero "Debe ser llamado dignamente teólogo no aquel que contempla la realidad invisible de Dios, gracias a la inteligencia de las cosas creadas, sino el que entiende la realidad visible y concreta de Dios gracias a la contemplación de la pasión y la cruz de Jesucristo", I, 354, 19 y 20 (se remite al volumen, página y líneas de la Kritische Gesamtausgabe editada en Weimer 1883 y ss.).

(29) Conf. L.Serenthà, Atributos de Dios, en Diccionario Teológico Interdisciplinar I, Salamanca 1982, especialmente 532-535. 
do por el Hijo y recibido por el Padre ... La cruz dice por lo tanto que la Trinidad hace suyo el exilio del mundo sometido al pecado, para que este exilio entre en la Pascua a la patria de la comunión trinitaria. La cruz es historia porque es historia trinitaria ... proclama ... la buena nueva de la muerte de Dios, para que el hombre viva de la vida del Dios inmortal..." (30).

\section{LA MUERTE DE JESÚS}

El discurso neotestamentario sobre la muerte presupone un desarrollo y evolución sobre la muerte del hombre que se perfila en los escritos del Antiguo Testamento y que va de una sombría resignación ante la misma ya sea como secuela de su creaturidad o de su pecado y culmina en una esperanza en la resurrección de los muertos (31). En el mismo Nuevo Testamento el discurso sobre la muerte se centra en una muerte concreta y singular, la muerte de Jesús. Sobre la significación estrictamente teológica -no la inmediatamente asequible vía método histórico-crítico- de la muerte de Jesús (32) destaca por su envergadura especulativa la reflexión que ofrece E. Jüngel. Me permito esbozarla a continuación.

En su libro Dios como misterio del mundo, Jüngel, después de referirse al discurso hegeliano sobre la muerte de Dios, se pregunta él mismo: “¿qué puede aprender la teología" apropiándose "del discurso de la muerte de Dios?". A su parecer, dos cosas: en primer lugar, "la teología tiene que tomar el ateísmo más en serio de lo que él se tomaría a sí mismo" (33). Y este es el aspecto que más se considera en esta obra. A juicio de Jüngel, "las oscuras palabras de la muerte de Dios entrañan una problematización no de la existencia divina, sino de la esencia de Dios... el concepto tradicional de la esencia divina no permitía el contacto o tangencia de Dios con la realidad de lo perecedero" (34). Hegel sería el primero en replantear "en toda su radicalidad" la posibilidad de unir "la idea (Gedanken) de Dios con

(30) B. Forte, Trinità come storia. Saggio sul Dio cristiano, Turín 1985, 39-40.

(31) No es del caso desarrollar aquí este tema. Me permito remitir a la reseña de El mundo creación y promesa de Dios, Santiago de Chile 1996, 376-398.

(32) Con ello no pretendemos abstraer del significado que tiene la concretísima "pro-existencia" de Jesús como concepto cristológico-fundamental que sella y conjuga la vida, la acción y la muerte de Jesús así como su misma realidad como Señor resucitado. Todo esto lo ha explicitado magistralmente H. Schürmann (ver "La 'pro-existencia' como concepto cristológico fundamental" en El destino de Jesús: su vida y su muerte, Salamanca 2003, 267-301) Más bien, atrevidamente, he pretendido acoger el desafío que dirige el mismo Schürmann como teólogo bíblico a los sistemáticos cuando escribe: "La pro-existencia nos remite primariamente al exsistir, que es cosa distinta del sub-sistir en reposo por parte del individuo racional (de la 'naturae rationalis individua substantia', de Boecio). No en el sub-sistir- tan solo en el exsistir- llega el individuo racional subsistente a convertirse en per-sona trascendente y existente. Dentro de tal comprensión, el término pro-existencia puede servir para una 'teología teológica' dialógica, que sobrepase a una teología de enfoque ontológico y antropológico" (270). Es precisamente en este horizonte donde me he permitido hablar de "condiciones pro-existenciales de credibilidad" para designar "las que, teniendo también su fundamento en la misma persona de Jesucristo, se explicitan mediadas por una determinada condición histórica en cuanto positivamente concernida y sellada por el pro-existir de Jesús". (La fe en busca de inteligencia. Atisbos teológicos, Santiago de Chile 2005, 110.

(33) Dios como misterio del mundo, Salamanca 1984, 133-134

(34) O.a.c., 137. 
el concepto de cambio (Veränderung), cuya representación extrema sería el acontecimiento de la muerte" (35). En base a la negación de la existencia de Dios, Hegel "está buscando determinar de un modo nuevo y radical la esencia" divina.

Esta nueva determinación pretende superar la aporía a la que llega una reflexión "natural" sobre Dios. En el concepto tradicional de esencia divina hay una "postura implícita", que Jüngel llama "estar sobre" y que excluye cualquier negatividad en dicha esencia. El ateísmo, pues, no sería más que la expresión de lo intolerable que se torna la idea tradicional de la esencia divina. De allí deriva, para Jüngel, la necesidad de superar tanto el teísmo tradicional como el ateísmo.

El segundo aspecto que Hegel recuerda a la teología con su discurso de la muerte de Dios, es el "origen cristológico de estas palabras". Jüngel desarrolla este tema con mayor detención en su escrito titulado Tod. Brevemente nos referimos a lo que se expone en este hermoso libro. En el capítulo quinto (36), Jüngel hace referencia a la muerte de Jesucristo. Ello le proporciona la posibilidad de mediar entre la muerte y Dios, en la medida en que la muerte se entiende como "pasión de Dios". A la pregunta antropológica: “¿qué significa la muerte de Jesucristo para la muerte que todos nosotros tendremos que morir"?, corresponde una radical aproximación teológica: "sin la muerte de Jesús... simplemente no se llegaría a una genuina comprensión cristiana de la palabra 'Dios"” (37).

Más adelante, y una vez que recuerda que la resurrección no suprime sino que da todo su peso a la muerte de Jesús, Jüngel anota que el acontecimiento pascual, en cuanto obra del Padre en favor del Hijo, "pone de manifiesto la relación de Dios con la muerte de Jesús de Nazareth" (38). Ahora bien, esta relación no es otra que una identificación: Dios se identifica con Jesús muerto. De este modo, el anunciador del Reino de Dios deviene el Anunciado. Se trata de una "identidad paradójica": la vida de Dios se hace una sola realidad con un muerto. Esta identidad entre el Dios vivo y Jesús muerto "pone a Dios en contacto con la muerte" (39).

Ello supera aquella lejanía entre Dios y la muerte, propia del enfoque veterotestamentario: "Mientras que en el Antiguo Testamento Dios se encuentra infinitamente lejano de la muerte y aparece intocado por la mortal arrelacionalidad, en la muerte de Jesús asume el contacto de la muerte. En la medida en que Dios se identifica con Jesús muerto, se expone a la agresiva lejanía de la muerte: Dios expone la propia divinidad a la fuerza de la negación" (40).

Esta identificación no es un acontecimiento arbitrario, sino que se produce "por todos los hombres". De esta manera, "en la medida en que Dios se identifica con Jesús de Nazareth, hombre muerto en favor de todos los hombres, se manifiesta como el ser que ama infinitamente al hombre finito". El amor, que es motor no solo del actuar sino del ser mismo de Dios, es lo que se manifiesta, rompiendo, así, tanto la prohibición aristotélica de movimiento impuesta al ser divino, como la lejanía radical entre la muerte y Dios afirmada por el Antiguo Testamento.

(35) O.a.c., 138

(36) Tod, Stuttgart 1985, 121-144.

(37) O.a.c., 121.

(38) O.a.c., 131.

(39) O.a.c., 137.

(40) O.a.c., 138-139. 
El contacto entre Dios y la muerte, que se produce en la muerte de Jesús, comporta una tensión o lucha: amor y destrucción chocan a tal grado que se cuestionan recíprocamente. Pero "la victoria de Dios sobre la muerte consiste, precisamente, en que Dios soporta en sí la negación de la muerte" (41). Lo que en la muerte de Jesús se sacrifica es la trascendencia, la intangibilidad y la absolutez divinas. Se manifiesta un Dios del hombre que sufre por el hombre. Esto es lo que hace que la muerte de Jesús nos concierna a cada uno de nosotros: porque concierne a Dios.

Sobre la actitud con que Jesús enfrentó su muerte, Jüngel piensa que no es mucho lo que puede precisarse. En todo caso, no cabe imaginarse a Jesús como un héroe que muere; su muerte en nada se asemeja a la del idealizado Sócrates: lo más probable es que Jesús "murió gritando" (42).

Después de su muerte, Jesús se convierte, de anunciador del reinado de Dios, en el Anunciado. Esto se explica por la fe pascual: "la fe en la resurrección de Jesús por Dios no expresa otra cosa que la relación de Dios a la muerte de Jesús Nazareno" (43).

Ahora bien, la muerte de Jesús no solo establece la condición negativa de la fe en Jesús, sino también la condición positiva, no en sí misma, pero sí en la medida en que sus discípulos no se quedan en la fuga, sino que reconocen que "Dios se ha identificado con Jesús muerto" (44). Jüngel insiste en la misma página: "Es importante que quede claro que la fe en Jesús no surge al lado de la fe en Dios, sino que en la fe en Jesús no se trata de otra cosa sino de la misma fe en Dios".

En un último acápite -"La muerte y Dios"-, Jüngel insiste en que la dimensión soteriológica de la muerte de Jesús reside en dicha "identidad paradójica", que, por lo demás y en cuanto tal, se entiende también como la relación entre Dios y la muerte del hombre. A diferencia del Antiguo Testamento, en el cual Dios y la muerte se contraponen, el Nuevo Testamento establece que "en la medida en que Dios se identificó con Jesús muerto, se expuso realmente a la agresiva lejanía divina de la muerte (es decir), expuso la propia divinidad a la fuerza de la negación" (45). De este "exponerse" de Dios a la muerte deriva una novedad: "Cuando Dios no cesa de relacionarse (verhalten) con nosotros, ni siquiera en la muerte, cuando se identificó él mismo con Jesús muerto, para así a través del Crucificado mostrarse próximo (gnädig) a todos los hombres, entonces surge del medio de la no-relacionalidad (Verhältnislosigkeit) de la muerte una relación de Dios al hombre". Esta nueva relación consiste en que "Dios soporta él mismo aquella alienada no-relacionalidad de la muerte: donde las relaciones se rompen y los nexos acaban, precisamente allí interviene Dios".

De esta manera, Dios revela su propio ser: "En la medida en que Dios se identificó con Jesús muerto en favor de todos los hombres, se revela ahí mismo como un ser infinitamente amante del hombre finito". El amor no es solo el motivo del actuar de Dios, sino su mismo ser. A juicio de Jüngel, esta nueva relación "a Dios" está precontenida en la afirmación que la Iglesia primitiva hace de la encarna-

(41) O.a.c., 142.

(42) O.a.c., 133.

(43) O.a.c., 131.

(44) O.a.c., 137.

(45) O.a.c., 139. 
ción divina: "El que Dios se hizo hombre implica que Dios comparte con el hombre la miseria de la muerte" (46).

La victoria de Dios sobre la muerte reside precisamente en que "Dios soporta en sí la negación de la muerte". Aludiendo a 1 Cor 15, 55, Jüngel comenta: "la muerte ha dejado su aguijón, el instrumento de su dominio, en la misma vida de Dios" (47).

Esto se entiende en la perspectiva paulina: "El pecado es agresión contra Dios. Por eso conduce a la muerte; (el pecado) es el aguijón de la muerte, con el cual esta impera (...) Al sufrir este aguijón, en el hecho de soportar esta negación que se dirigía contra Él, Dios le ha quitado el poder a la muerte, y a la vez se ha revelado por sobre todo como Dios: Dios es el amante del hombre y, por ello, el que sufre por él" (48). Dios se revela no como Aquel que no puede sufrir, sino como Aquel "que puede sufrir infinitamente".

Jüngel piensa que si tiene sentido hablar de "sacrificio" en relación a la muerte de Jesús, no se debe entender como un sacrificio a un Dios que requeriría de expiación, sino como el sacrificio que Dios mismo hace de su trascendencia, intangibilidad y absolutez. Se trata del "sacrificio de la total contraposición de Dios con respecto a la creatura pecadora".

\section{VIDA Y MUERTE}

Recopilemos los pasos dados hasta aquí en la reflexión teológico-fundamental emprendida antes de concluir con la misma. En primer término constatamos que la vida y Dios se establecen como realidades que se condicen no como entidades abstractas sino históricas. Ambas realidades acontecen y así son. Este dinámico condecirse de Dios y la vida no excluye la muerte como realidad que esencialmente atañe al hombre, sino que lo confronta con el sentido de su radical finitud e inmanencia y, a la vez, cuestiona el significado de la afirmación que se haga de la infinitud y trascendencia de Dios. Ahora bien, la afirmación de fe en el Dios de Jesucristo no parece ser incompatible con afirmar un morir de Dios, sino que, al superar el esquema de una divinidad inmutablemente apática y ajena al destino de muerte que aflige al hombre, más bien resuelve la contradicción entre vida y muerte en tanto postula una identificación de Dios con un hombre muerto, Jesús de Nazareth, a quien proclama resucitado. De este modo da nombre a la unidad de la diferencia de vida y muerte estableciendo la persona de Jesús como concreta clave de "desparadojización" de la fe cristiana (49). Así se supera un recurso

(46) O.a.c., 140

(47) O.a.c., 142

(48) O.a.c., 143

(49) Como bien constata N. Luhmann: "La reflexión de la religión habría fallado a su objeto (y con ello a su propia operación) si quedase aprisionada en la paradoja y tendría que concluir que la religión es imposible. Ella empero se sobrepone en la medida que 'da nombre' a la unidad, a la unidad de la diferencia de inmanencia y trascendencia. Con este dar nombre es llevado a cabo lo que primariamente hace que la religión sea religión: la desparadojización de su propio código", "Die Ausdifferenzierung der Religion" en Gesellschaftsstruktur und Semantik B.3, Suhrkamp 1989, 314. Al respecto me permito remitir a lo expuesto en "Sobre la credibilidad del dogma cristiano", en Teología y Vida 45 (2004) 268-271. 
meramente negativo y abstracto a la paradoja que termina por confinar la fe al subjetivismo (50).

Prolongando el planteo de Jüngel anteriormente mencionado es posible afirmar que Dios al identificarse con Jesús muerto se apropia de la muerte del hombre, la de todos y cada uno, y así esta, la muerte de todos y cada uno, ya no queda más referida a sí misma, sino que se perfila y transforma como una muerte en Dios. Con ello la infinitud propia del Dios de Jesucristo no se verifica como neutra, sino como infinitud amante que acoge y reafirma nuestra frágil finitud como propia en su infinitud todopoderosa. Como lo proclama poéticamente el himno pascual la unidad de la diferencia entre vida y muerte acontece de una vez para siempre y para todos en la muerte y resurrección de Jesucristo: "mors et vita duello conflixere mirando: dux vitae mortuus regnat vivus" (muerte y vida lucharon en duelo prodigioso: el autor de la vida muerto reina vivo).

\section{RESUMEN}

La vida y Dios se establecen como realidades que se condicen no abstracta sino históricamente. Ambas realidades acontecen y así son. Este dinámico condecirse de Dios y la vida no excluye la muerte como realidad que esencialmente atañe al hombre, sino que lo confronta con el sentido de sus radical finitud e inmanencia y, a la vez, cuestiona el significado que se haga de la infinitud y trascendencia de Dios. Ahora bien, la afirmación de fe en el Dios de Jesucristo no parece ser incompatible con afirmar un morir de Dios, sin que, al superar el esquema de una divinidad inmutablemente apática y ajena al destino de muerte que aflige al hombre, más bien resuelve la contradicción entre vida y muerte en tanto postula una identificación de Dios con un hombre muerto, Jesús de Nazareth, a quien proclama resucitado. De este modo da nombre a la unidad de la diferencia de vida y muerte estableciendo la persona de Jesús como concreta clave de desparadojización de la fe cristiana.

\section{ABSTRACT}

Life and God are established as realities that fit together not in an abstract way but, rather, historically. Both realities occur and thusly exist. This dynamic harmonization of God and life does not exclude death as a reality that concerns humanity, but instead confronts humanity with the sense of its radical finitude and immanence, and at the same time questions the meaning made of God's infinitude and transcendence. Now, the affirmation that faith in the God of Jesus Christ does not seem incompatible with affirming a death of God, but rather-upon overcoming the plan of an immutable divinity, apathetic and distant from the destiny of death that so afflicts humanity-resolves the contradiction between life and death inasmuch as it posits an identification on God's part with a dead man, Jesus of Nazareth, whom this faith proclaims resurrected. In this way it gives a name to the unity of the difference of life and death, establishing the person of Jesus as the concrete key to the de-paradoxization of Christian faith.

(50) Como genialmente lo expresa I. D. Zizioulas sintetizando el significado de vida en el planteo de Ireneo de Lyon: "Cristo es la verdad no porque sea un principio epistemológico que explique el universo, sino porque es la vida, y el universo de los seres halla su sentido gracias a su existencia incorruptible en Cristo que recapitula toda la creación y la historia. No se puede concebir el ser al margen de la vida, y por ello la naturaleza ontológica de la verdad se encuentra en la idea de vida”, El ser eclesial, Salamanca 2003, 92. 
